\title{
Octapharma's balanced portfolio built on a very special juice
}

Kate Khair

\section{Octapharma's core business is the development and} production of human proteins from human plasma and cell lines. As the company moves into the recombinant arena, Chairman Wolfgang Marguerre discusses opportunities and threats with Editor-in-Chief Kate Khair

How did you get involved with the plasma industry?

I first became involved in 1975 as manager responsible for the distribution of blood products for Baxter-Travenol Europe as their Director and Business Manager of Hyland-Division. Despite an academic background of Politics \& Economics rather than science, I recognised the potential patient benefits of introducing viral inactivation to plasma products. At that time manufacturers of plasma products were not dedicating resources to viral inactivation. I strongly believed that investigating and developing a robust viral inactivation process was the right course of action. This conviction led me to establishing Octapharma in 1983.

How important are bleeding disorders to the Octapharma product portfolio?

I founded the company as a response to the tragic situation facing the haemophilia community in the early 1980s. Our first product was the first factor VIII concentrate using what at the time was innovative solvent detergent virus inactivation technology. The name Octapharma is in fact taken from the Greek word for eight, named after the factor which is deficient in haemophilia A patients. The treatment of bleeding disorders remains profoundly important to Octapharma but of course we now have a wide portfolio of products in the areas of

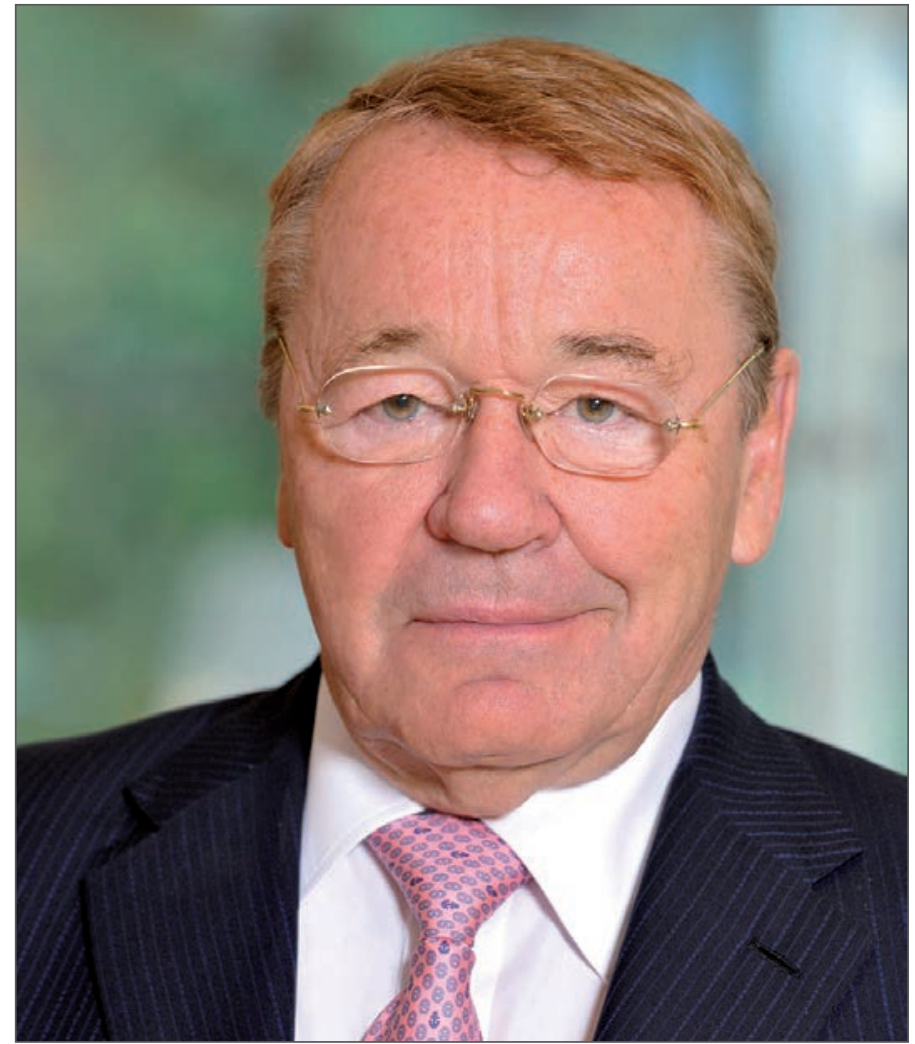

Wolfgang Marguerre was born and educated in Heidelberg. In 1983 at the height of the contaminated blood disaster he founded Octapharma, with the aim of enhancing patient safety. He personally sponsors 70 children with bleeding disorders in India, Nepal,

Romania and the Philippines through Save One Life, an international non-profit organisation that supports children and adults with blood disorders. haematology, immunotherapy and critical care.

Is factor or IVIG more important for you/your company and why? It would be incorrect to say one is more important than the other. When Edwin Cohn developed plasma fractionation in 1944, when I was only 3 years old, he provided the technique that today allows us to extract the different classes of proteins present in plasma. Cohn had written on his blackboard "Das Blut ist ein ganz besonder Saft" meaning, "Blood is a very special juice." We tap into the human body's unique source of invaluable proteins to make a range of products. For every litre of plasma donated we must ensure we are using as much of the protein as we can; to waste any of this gift of life is undesirable. Therefore the balance of our portfolio is vital. Although $50 \%$ of our sales are in IVIG, it would be unsustainable to sell only IVIG products. The real importance is keeping the balance of the portfolio which is the balance determined by nature.

What are the biggest challenges facing the plasma industry in 2014 and how can these be overcome?

The biggest challenge facing the plasma industry in 2014 is the increasing global demand for plasma products. It is our responsibility as the world's largest privately owned plasma fractionation 
company, to ensure that we are in a strong position to support the needs of patients around the world. First we must look at plasma supply. The company is increasing plasma availability by sourcing higher volumes of plasma, for example our plasma centres in the US provide $75 \%$ of our overall plasma supply and we are increasing our plasma production across all 45 of our US plasma centres. We are investing significantly into increasing plasma fractionation capacity of our production plants to convert more source plasma into product. We are investing 400 million Euro for Program 2019, which by 2019 will more than double the corporation's plasma throughput capacity.

What do you see as the most important product characteristics of plasma-derived products in haemophilia care? Importantly, plasma-derived products have demonstrated over many years that haemophilia treatment care can be delivered to meet the challenges of all. The increasing desire to maintain the humanity connection has resulted in the development of our first human cell-line recombinant FVIII.

Octapharma has now developed a human recombinant factor VIII. Do you believe there is still a role for plasma derived factors in the recombinant age?

Absolutely, there is still a very important role for plasma. Our philosophy is "from human to human" whether that be human protein from plasma or from a human cell line. By moving into the new world of recombinant, we are diversifying and counterbalancing the issues faced globally in plasma supply. We are in parallel continuing to invest heavily in our plasmaderived portfolio in R\&D and life-cycle management. Entering the recombinant business allows us to present an enhanced overall global portfolio combining both plasma-derived and recombinant products which ultimately gives healthcare providers more flexibility and choice in their patient's treatment.

Where do you think haemophilia care will be in 10 years time?

Today, with access to replacement therapy people with haemophilia can now live relatively normal lives. However inhibitor development is the greatest threat to treatment - effectively neutralising the infused factor. I believe that with the right investments and research inhibitor

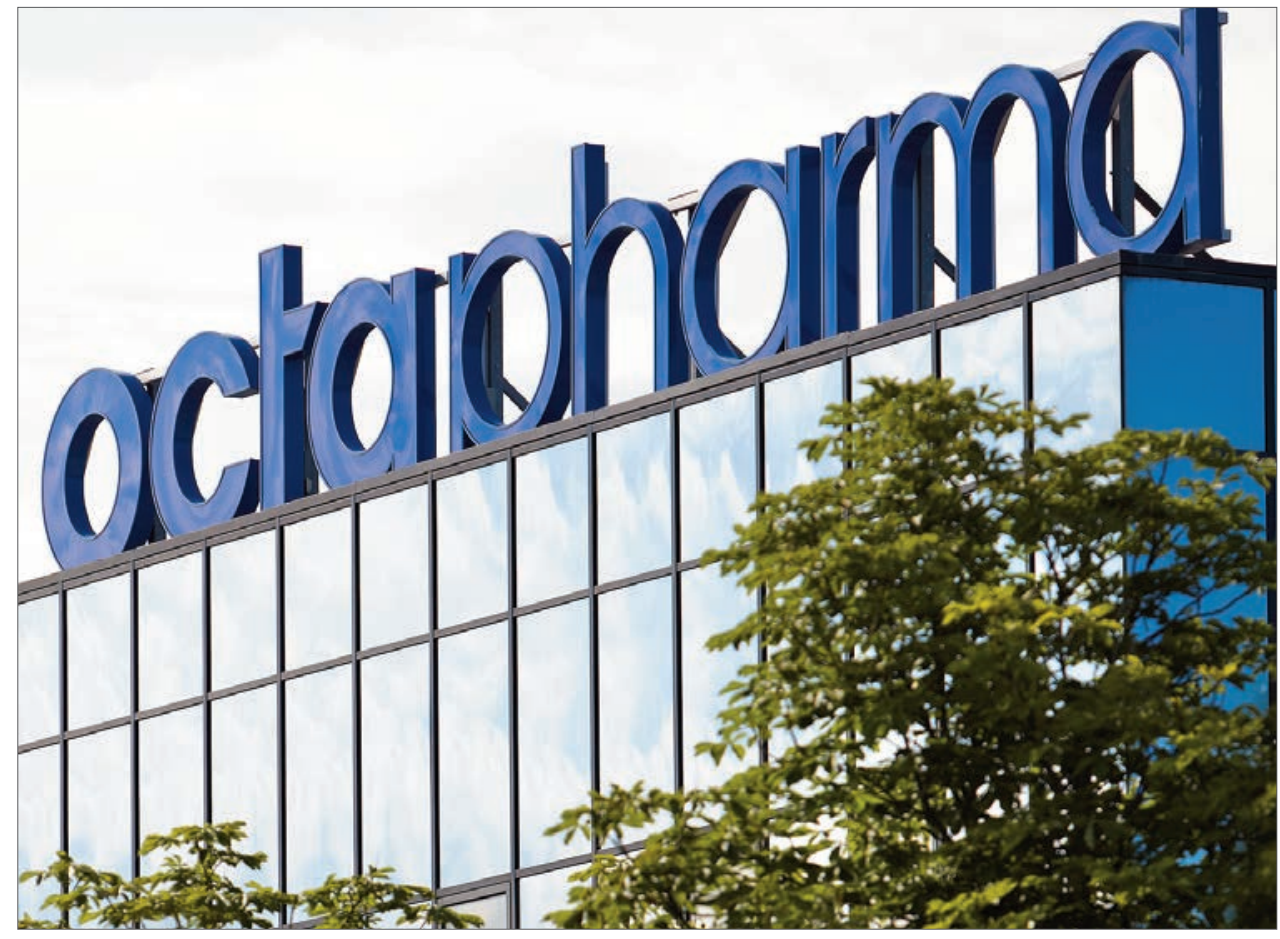

\section{"We do not think of ourselves as simply manufacturers of product... Setting up the right auxiliary services is a key part of what we are doing globally"}

development can be dramatically reduced and perhaps eradicated. Our research and development programme aims to support this. I also envisage an increase in personalised prophylactic care in haemophilia treatment, since individualised treatment could significantly improve the quality of life for every person living with haemophilia.

How do you see Octapharma in 10 years time?

When my two sons take over the leadership of the family business I am confident that they will continue to uphold the values that have driven Octapharma from the beginning. Today, we are preparing for the next stage in Octapharma's development. There are still huge growth opportunities and we are putting robust structures in place now that will allow us to continue to grow while maintaining our flexibility and entrepreneurial spirit.

What changes would you like to see in haemophilia care in the developed world? I would like to see replacement factor available to all people living with haemophilia and improved access to individualised expert care and treatment regardless of where you live. As a manufacturer we share responsibility in supporting the attainment of this vision and continue to direct our resources into improving our capability to meet increasing demands and establishing improvement to current treatment options

Do you ever foresee a time when product manufacturers will play a greater role in service provision?

We do not think of ourselves as simply manufacturers of product, in fact I believe it is our responsibility to be much more than that. We operate in a very delicate segment of the biopharmaceutical industry and our fundamental core qualities are trust and reliability.

Part of establishing trust is establishing meaningful long term relationships with stakeholders; we strengthen these relationships by developing reliable and innovative products and providing services associated with treatment. We deliver patient focused programs like education programs and improved diagnostics. Setting up the right auxiliary services is a key part of what we are doing globally. And as the company's global footprint 
grows, our involvement in these activities will also grow.

Threat or opportunity? What are your thoughts on the growing trend towards national tendering for bleeding disorders products?

Understanding the complexity of different procurement objectives is important. By working closely with dedicated healthcare professionals you identify with the

differing needs or objectives of the chosen method.

In Octapharma we have managers with many years of national and regional tender experience. They are able to harness this knowledge and expertise alongside their understanding of patient needs across the varied procurement options that we are engaged in.

Recombinant products for the treatment of VWD will soon be available. What is the rationale for developing plasma-derived products to treat VWD?

von Willebrand disease - and especially in its severe form - is a dual deficiency of both: von Willebrand factor (VWF) and Factor VIII (FVIII). Our treatment philosophy for patients with VWD is to provide them with both coagulation proteins in their native and well-preserved form, which is the VWF/FVIII complex in the physiological 1:1 ratio. This is ensuring the immediate presence of both coagulation proteins at the same time in order to stop or prevent bleeding in these patients.

The under-treatment of bleeding disorders remains a major challenge in developing countries. What needs to

\section{"Globally, 75\% of people with bleeding disorders do not have access to treatment. It is in the countries where treatment is not widely available that you really come to appreciate what a monumental difference treatment can make in a person's life"}

happen to improve the situation in developing countries?

The disparity between the availability of treatment for bleeding disorders in the developed world and that of the developing world is huge. Globally, $75 \%$ of people with bleeding disorders do not have access to treatment. It is in the countries where treatment is not widely available that you really come to appreciate what a monumental difference treatment can make in a person's life. With access to proper treatment, patients' lives can be significantly improved.

What is required in the developing world is proper diagnosis, reliable access to treatment, disease management and adequate care by specialists in the field. Healthcare providers need to be trained to both diagnose and treat conditions, in particular rare disorders.

In addition, patients need to be empowered through education on how to live healthier and more productive lives. This is why the work of organisations like the WFH is so important, and this is why we have supported the activities of WFH for many years. We are all looking forward to this year's WFH World Congress in Melbourne Australia in which Octapharma is a platinum sponsor.

In your 30 years as owner of Octapharma, what are you most proud of?
When I founded Octapharma in 1983 I had no way of knowing the difference we would make. I am proud to have seen Octapharma grow from a few people who believed in improving patient safety for people with haemophilia A, to the over 5,500 employees globally. Despite the incredible growth, our core remains because our focus has not changed in 30 years. We continue to be dedicated to improving the lives of patients. The 30 year anniversary in 2013 was an opportunity to feel pride in how far we have come but also to look to the future. There is no place for complacency or selfcongratulation. So I am most proud to be in a position now to harness our profits into strategic areas to build for the future and to continue to invest in research that will fulfill unmet patient needs.

Can you tell us about your work with Save One Life?

Since 2009, Octapharma has been a corporate sponsor of Save One Life, an international non-profit organisation that provides direct support to children and adults with bleeding disorders. In addition, I personally sponsor 70 children with bleeding disorders in India, Nepal,

Romania and the Philippines. The activities are aligned with the founding principle of Octapharma as a patient-centred organisation dedicated to improving patient care.

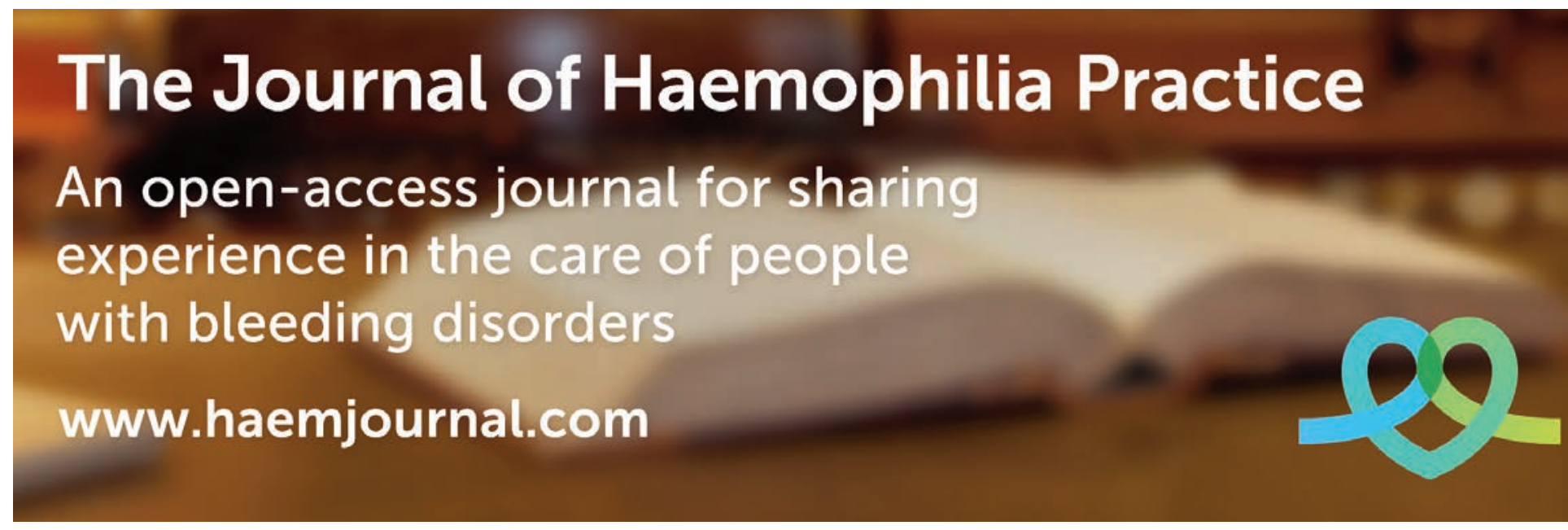

